\title{
EMERGING AND SUBMERGING: EBBS, FLOWS, AND \\ CONSISTENCY IN EXPRESSIONS OF INDIGENOUS IDENTITY
}

\section{Hilary N. Weaver}

As I reflect on the topic of contemporary, emergent indigenous identities, I am flooded with a multitude of stories, most of them painful: the light-skinned, blue-eyed Native woman who presents her enrollment card to administrative staff in her own tribe when she goes to pick up her annuity yet is challenged about her authenticity and legitimacy; the Native man who uses his language fluency as a weapon to degrade and humiliate his Native wife who does not speak her own language; the youth who argue about whether it is possible to be both Native and American; and the respected, traditional elder who asks the venom-laden question, "are you Indian or are you Christian?" Contemporary indigenous identities are multifaceted and are shaped by societal pressures, internalised oppression, cultural pride, and a host of other factors.

While it would be an impossible and contentious task to reflect on all, or even most, aspects of contemporary indigenous identity, I accept the challenge and honour of being asked to share my perspectives. While in my academic life I have done research and writing related to identity issues, it is likely my own life experiences and reflections that primarily fuel this chapter. Of the many identities that I bring to this chapter, some of the most salient are that I am Lakota (by birth), Seneca beaver clan (by adoption), urban, of mixed heritage, a member of the Longhouse, and a mother. 
As I reflect on the topic of emergent identities I feel compelled to examine how the emergence of today is firmly grounded in the submergence of indigenous identities in the past. I also question how being Native American/Indian/Indigenous/First Nations has been defined (often in constricted ways that reflect oppression and internalised oppression) and how we might be able to emerge from these oppressive constraints. I examine how identity is reflected in names and appearances, and ultimately reflect on what this means for future generations. These are my thoughts, for what they are worth.

\section{Contemporary Emergence as Grounded in the Submergence of the Past}

Indigenous people of today have more freedom and ability to express their identities than Native people of the past few generations. In the United States, as in many other colonial societies, most expressions of our indigenous identity such as language, spirituality, and cultures were suppressed. Those who attempted to assert their identities were often severely punished. Native children who spoke their languages in boarding schools were beaten. Native people who asserted their spirituality faced legal repercussions. Native people who maintained their cultures, were taunted as backward and uncivilised. For the past century and more, it has often been difficult, and at times unsafe, to visibly and audibly embrace Indianness.

My grandfather was born in October, 1891, nine months after the infamous massacre at Wounded Knee in present day South Dakota. It was a difficult time to be Lakota. As the oldest of nine children, he suffered from malnutrition and rickets that would leave his legs twisted and bowed for the rest of his life. Poverty was a constant. In hindsight, I reflect on this time as a crossroads where indigenous people faced stark questions about their survival. Demographers tell 
us that our population numbers were at their lowest at the turn of that century. Was there a future for the Lakota people?

After attending boarding school, my grandfather developed a zeal for education. For him (and for my grandmother whom he met at boarding school) survival and assimilation were synonymous. In order to survive, indigenous identity must submerge. When he returned to his homeland (what became known as Rosebud reservation) in the 1930s, he did so in the guise of an American. Education and assimilation seemed (to him at least) the only options. As an employee of the Bureau of Indian Affairs, his indigenous identity was submerged under the rising tide of Americanism. Indeed, I am convinced that at that time he saw no safe alternative, as the slogan "the only good Indian is a dead Indian" continued to ring throughout the country.

In hindsight, as an alternative to a generation of "dead Indians" we now have a generation (or generations) of "submerged" Indians. In writing this chapter on emergent indigenous identities, I must respectfully acknowledge the submerged indigenous identities, those who did not have the freedom, safety, and/or privilege that those of my generation have to emerge.

\section{Stepping Out of the Box}

Ideas about Native American identity often seem relegated to a very small box. After all, we "know" what an Indian should look like, just as we know that Indians are spiritual, live in harmony with the earth, and have a tendency to be war-like. We seem to have a hard time moving beyond a very narrow set of stereotypes when it comes to thinking about indigenous identity. 
Perhaps we could benefit from examining how some scholars and activists have begun to think out of the box when it comes to gender. Rather than a dichotomous variable of male/female, they have encouraged us to think in terms of a spectrum of gender expression. Stepping outside the box, we are challenged with labels like "gender queer". Perhaps pushing beyond conventional definitions of gender provides a model for moving beyond static and stereotypical ideas about what is "Indian" and what is "traditional". How might breaking out of our own box reshape our thoughts about being indigenous? How might we reflect on questions of what it means to be traditional and who decides this?

To be clear, I do see great value in "traditional" beliefs and cultures of indigenous people. I think there are core aspects of our cultures that make us distinct. The very fact of being indigenous (i.e., people of the land) shapes our values, beliefs, and existence, as well as our legal status in ways quite distinct from members of colonial societies. However, I am concerned, dismayed, and angered when we internalise oppression to the point of saying that one way of being indigenous is superior or more authentic than another. In a mixture of internalised colonisation and feelings of inadequacy, it is common for some people to question the legitimacy of others' indigenous identities or "Indianness" as a way to define and assert their own (Carpenter 2005).

There is quite a list of ways in which some Native people don't live up to someone else's standard of being Indian enough. You are likely to be told that you are lacking, not good enough, not traditional, or not a real Indian if:

- You don't speak your language

- You don't live on a reservation

- You live away from your traditional territory

- You are of mixed heritage 
- You have successfully attained a college degree or beyond

In some cases you are also considered less than a real Indian if you are baptised or follow Christian beliefs rather than traditional indigenous spirituality.

Ideas about where someone lives and its relationship to their "Indianness" are of long standing. Even in the 1920s, a woman claiming an indigenous identity yet living in New York City came under scrutiny for her authenticity (Carpenter 2005). In spite of longstanding federal policies that encouraged Native people to leave their reservations and relocate to urban areas, there often remains a presumption that an indigenous person living on a reservation is more authentic than one living in a city.

In fact, there are a multitude of reasons why contemporary Native people present some or perhaps all of the above listed "non-Indian" traits. There are many of us, myself included, who "don't fit the mold" of what we are told an Indian is. We need to raise the question, "Who created a static, rigid mold anyway?" Was it "them"? Is it "us"? It is likely that static, stereotypical visions of indigenous identity are maintained both by outsiders and by insiders for a variety of reasons that space does not permit elaborating on in this chapter. Suffice it to say, it is not enough to claim that outsiders have limited our ideas about indigenous identity-we need to reflect on how our own beliefs, attitudes, and behaviors as indigenous people limit our understandings of how indigenous identity is and could be expressed.

\section{The Dichotomous World}

We often conceptualise the world in dichotomous terms that reflect who is an "us" and who is a "them"; who is indigenous and who is not. While the illusion of clarity can seem reassuring, it leaves no room for 
gray areas and keeps us confined to thinking in terms of the aforementioned box. People of multicultural and/or multiracial heritage have fought against being forced into either/or choices about their identity, insisting instead on asserting an additive or multiple identities. Their battles have been met with varying degrees of success. For example, while some forms now allow people to "check more than one box" to reflect their identity, they often still face attitudes of others that expect them to state which one they "really" identify with, or they are assumed to fit a particular identity based upon skin color, hair texture, or phenotype.

Some traditional teachings also encourage us to think in terms of static, inflexible models of indigenous identity. Among the Haudenosaunee (aka Iroquois Confederacy) ideas about indigenous identity are commemorated in the Two Row Wampum belt. When Europeans first came to North America in their ships hundreds of years ago, the indigenous people met to determine how they would respond to the newcomers. It was decided that the Europeans would be allowed to live and follow their own ways of life and traditions. Conversely, the indigenous people would continue to live independently and apart from the Europeans, following their own ways of life and traditions. Neither way of life was considered superior to the other; they were simply different. The Europeans had their ships and the Haudenosaunee had their canoes. If an indigenous person chose to live the lifestyle of the newcomers that choice would be respected. Likewise, a European who chose to leave behind his or her own ways and live with the Haudenosaunee and following their traditions, would be welcome. Either way was equally valid, but a choice had to be made.

The Two Row Wampum belt shows two parallel lines: the two types of boats. You do not stand with one foot in each boat. To do so is 
foolhardy and you will inevitably fall into the water. You must make a choice. While I do not mean to suggest that this is the only interpretation of the Two Row Wampum belt, it is one that is commonly used to define indigenous identity as separate and never intersecting with other ways of being. This becomes a virtually impossible mandate for contemporary indigenous people as we try to find our way in an increasingly global society.

I continue to fall in the water as I struggle to maintain traditional beliefs, practices, and spirituality while living in a multicultural urban environment and teaching at a major research university. While it continues to be an uphill battle, I try to balance attendance at ceremonies with teaching classes and attending faculty meetings. I give thanks and harvest medicinal plants on days when a stack of papers is waiting to be graded. I constantly feel guilty that I am not adequately fulfilling my obligations on either side. Such is the price for trying to keep my feet in separate boats.

As a contemporary indigenous person, I will not choose one boat over the other but I do get tired of having a face full of water and wonder if the day will come when I will drown. In the meantime I keep trying and looking for some sort of life vest or nose plugs to help with the constant bombardment of water. Perhaps there is some hope as offered by a Navajo scholar who suggests that living by Navajo values while being immersed within the larger dominant society can actually serve to reinforce and maintain an indigenous identity (Lee 2006, 81). Indeed, living in two worlds (or negotiating two boats) has been identified as a virtual necessity for contemporary Native Americans. This ability to balance was found to be one of four crucial elements for Ute women in tribal leadership positions (Barkdull 2009, 130). In many ways, the contemporary existence of indigenous people is defined by continuous struggles to span different ways of being. 


\section{What's in a Name?}

The ability to claim or bestow a name can be powerful and filled with meaning (Braun 2008). Names are typically bestowed on us by others. It is odd that this representation of "us" comes from elsewhere, yet we are expected to "wear" it as a symbol of ourselves throughout our lives. Sometimes names have an "ethnic" ring to them. A certain name may communicate whether someone is likely to be Muslim, African American, or Irish. Common societal images and expectations tell us that Indians are supposed to have colorful names, often reflecting animals or parts of nature. You know you must be talking to a "real Indian" when you are introduced to Rufus Small Bear or Mary Running Deer. Individuals with anglicised names are asked if they also have an "Indian name". Even t-shirts advertised in mainstream catalogues reflect this way of thinking as we are encouraged to buy shirts that say, "My Indian name is Runs with Beer".

In a societal context where names have become so laden with stereotypes, what does this mean for an indigenous person whose name appears to reflect and reinforce the stereotype that Native people have colorful names? What does it mean for the Native person whose name does not reflect stereotypical ideas of what a Native person should be called (i.e., Smith, Johnson)? Is authenticity as an indigenous person (or lack thereof) tied in with the name that we inherit or is bestowed upon us?

What of people who carry both a name used in day-to-day life and have an indigenous name that has been bestowed upon them in a ceremony? Are they more legitimate than their cousins who, for what ever reason, have not been given a ceremonial name? Who does and does not have a name provides significant fodder for internalised oppression and battles over "Indianness". 
In contemporary times when assertions of indigenous identity have become safer, there are some families, mine included, who return to indigenous names as assertions of identity and cultural pride. My son does not have an English name (as indeed he is not English). He does not have an "American" name; a reflection of my beliefs and priorities. I gave him the name Wanblee to proudly reflect our Lakota identity, although as a compromise I did choose the spelling that I believed Americans were least likely to mispronounce. He also carries a Longhouse name bestowed on him by the Beaver Clan in Mid-winter ceremonies when he was a few weeks old. As a parent I feel I have given him a solid grounding in his indigenous identity that will allow him to stand strong and emerge as a proud indigenous person.

Names, as I noted above, are typically given to us by others although they are presumed to represent us. My son received his names from me and his clan. I think they fit him but he wears them with discomfort, at least at this stage of his life. Periodically he asks why he can't have a "normal" name, as if I have saddled him with a burden to bear. (Have I?) As he blurted out a couple of years ago, "Why didn't you just name me Tommy?" While they may assert it differently than adults, Native youth clearly experience the challenges of being indigenous in contemporary society.

\section{The Power of Visual Images}

Ideas about indigenous identity are intimately intertwined with perceptions of what an Indian should look like. Long brown hair, often braided, and tan skin (not too light and certainly not too dark) are the hallmarks of the Hollywood Indian and what we have come to expect Native Americans to look like. Additionally, Indians are much more recognisable when wearing lots of turquoise jewelry and perhaps some feathers in their hair. Fringe also makes a nice addition. Lest we think that it is only old-time Hollywood movies that perpetuate 
stereotypical images of Native Americans, the currently popular Twilight (2008) series reminds us that stereotypes are alive and well (LeValdo-Gayton 2011).

These stereotypical ideas have some grounding in reality, or at least the reality of the past. Native Americans (at least presumably the authentic ones) are frozen figures from a distant and romantic past. Perhaps this is why there is often difficulty recognising contemporary indigenous people who dare to appear different. Native people also play a role in perpetuating stereotypical images. In particular, a study of how tribes represent themselves on their official websites found that tribes with an incentive to attract tourists to casino gambling were likely to represent their own identities using historic and exotic images (Cuilleier \& Ross 2007). Apparently, some tribal officials believe that it is lucrative to perpetuate stereotypical images of indigenous people as romantic figures locked in time. It seems ironic that images of Native people as "other", previously used as justification for land appropriation and genocide, are now reframed as a way to entice tourists.

\section{In a New Community, in a New Day}

Contemporary indigenous people find themselves with considerably more freedom to express their identities than those from recent past generations. We also face additional challenges as we try to determine what it means to be indigenous in a multicultural society. A sense of community and feelings of belonging are typically identified as central aspects of an indigenous identity (Kenyon \& Carter 2011). This being the case, what are the implications for indigenous people who live outside of their traditional communities or perhaps outside of any indigenous community (either geographically or socially)? What does this mean for those mentioned earlier in this chapter whose right to belong to an indigenous community is challenged based on their skin 
tone, eye color, political bent, religious affiliation, or a host of other attributes presumed to be associated with an authentic indigenous identity?

Some scholars argue that indigenous values and philosophies should be one of the key components for measuring an indigenous identity (Horse 2005, Lee 2006). While this standard may in some ways be an improvement over the essentially valueless measure of blood quantum commonly used for tribal membership, evaluating someone's values to determine if they are Indian enough leads us into yet another quagmire.

I, like many of my contemporaries, live in an urban environment, in a territory that traditionally belonged to another indigenous group. I try to put a positive and unconventional spin on assimilation as I learn the traditions of my adopted homeland. Living in Haudensaunee territory, I participate in the Seneca Longhouse and raise my children within these traditions and life-ways. For me, this type of assimilation means adding to-rather than supplanting-my Lakota identity. My children both have Seneca names (as do I).

Recently, we traveled to our traditional Lakota territory in the Great Plains where we visited the town of Wanblee, South Dakota. Both my children reveled in the experience but especially my son Wanblee who posed for many pictures in front of the town sign with his name on it. A particular favorite is the picture taken in front of the "Wanbleemart Hot Stuff" sign-an advertisement for pizza at the local convenience store. At least on that day it was good to have the name Wanblee and to be in a place where people recognised the name. Now questions arise why my first-born, Iris, has a Seneca Longhouse name but not a Lakota name. All in all, I suppose our names, location, and limited language abilities (with smatterings of Lakota, Seneca, and 
Mohawk) reflect the realities of being a contemporary indigenous family in a multicultural world.

Speaking for myself, I feel empowered to express an indigenous identity. As a child and teenager in the 1960s and 1970s I often wore my hair braided and in braid-wraps (after all it was the 1960s and 1970s). It was a time when the activism of the Red Power movement impacted my family's life in ways more implicit than explicit. It was acceptable to tell people I was Lakota although I grew up knowing more about the Nez Perce, Couer d'Alene, Spokane, and Yakama people that surrounded my Eastern Washington community than I did my own heritage.

In 1973 my grandfather died. My parents and I drove across the country with my newly widowed grandmother. As an 11 year old, I had only a limited understanding of the adult conversations as we drove through South Dakota and listened to the daily news about the siege at Wounded Knee. My mother talked about how we were Iyeska, mixed-blood people who often served as a bridge or peacemakers between cultures-a role that was much needed at that difficult time. My grandmother had not been back to South Dakota since she was taken away to boarding school as a child. She had buried her past and rarely spoke about it. Driving through South Dakota and later attending powwows with us in the Northwest for the first time in more than 50 years she felt safe enough to begin to whisper about the past that had been left so far behind.

Beginning in the 1980s, my mother spent considerable time living, working, and reconnecting in the Lakota villages spread throughout the Great Plains. The re-emergence that began with my grandmother's whispers was soon echoed with my mother's confident voice. Although my path has been different, this foundation supports me. 
The Lakota women in our family are no longer content to be submerged, yet I still struggle to fill many voids. I know only a few words of my language. I have been told (in what I experienced as a harsh manner) that it is impossible to be Lakota without being fluent in the language. I was raised in an Episcopal household, a by-product of extensive missionary work conducted over the last century or so. I strive to learn my traditional customs but I learn with the difficulty of an adult fully grounded in Western ways and traditions rather than the ease of a child born into a holistic, nurturing indigenous culture. Like many of my generation I will always feel a deficit in my knowledge of language and culture. I find myself feeling fiercely indigenous and struggling with multiple, on-going insecurities at the same time.

I am not alone in feeling a great void in not speaking my own language. This is a common source of pain for many people in my generation. Lee (2006) also spends time reflecting on whether it is possible for someone to be Navajo, yet not speak the Navajo language. Indeed, if language and identity go hand-in-hand, what of the growing number of people who identify as Navajo but don't speak their language? Who are they, if not Navajo? Not only is language loss painful for those of us who cannot speak our "Native" language, it is also difficult for Native speakers who find themselves increasingly isolated and lonely as fewer people are able to converse with them. Language loss is detrimental to the wellbeing of Native people (Lee 2006), but to effectively write-off or disregard those of us who are not fluent in our languages as non-Native, quickly becomes a genocidal and/or suicidal practice.

While I struggle to fill my vast learning inadequacies and deficits, I believe that the best thing that I can do is to pave the way for the future. My children, while still grounded in a multicultural society, 
have access to language and culture in ways that I never did. They are raised in the Seneca Longhouse and attend Lakota ceremonies as well, when possible. Each day they hear the Seneca words, ga noh kwa, "I love you," and their traditional names are used. They are exposed to many different indigenous cultures as well as other traditions. I give them tools that I hope will prepare them for their future.

\section{What do we want for our children?}

The question arises, "What do we want for our children?" For me the answer is an ability to express their ndigenous identities without the painful insecurities that permeate my life as an indigenous person raised in the wrong place without the nurturance of my own culture and language. I am, however, constantly aware that my answer is quite different from how my grandparents answered this question. For them, the best choices that they could make for their children were survival through education and assimilation.

My grandparents deliberately raised my mother and her brother without the Lakota language and away from other relatives, as these were seen as barriers to survival in American society. Extended family members led lives heavily immersed in alcohol and violence. For my grandparents, providing a better life for their children meant separation from community, culture, and language. Assimilation was the way of the future; that way the children would not have to shoulder the same burdens of extreme poverty, racism, alcoholism, and violence.

Like my grandparents, I want to protect my children from the burdens that I experience: those of feeling lost and never quite good enough. In the end, future generations will make their own choices (and may very well make very different decisions) about how they will express their indigenous identities than the plans that I make. 
I'm not sure how indigenous identities will be expressed by future generations. It is my hope that my children and those who come after will retain the safety to be indigenous that my generation has been privileged to experience. It is also my hope that they will be able to proceed without the insecurities and internalised oppression so commonly experienced in my generation. Rather than thinking of ourselves primarily as independent individuals, many Native American nations have a concept of being linked to ancestors of the past and descendants of the future through seven generations. The teachings of the Seven Generations tell us that we must constantly plan for the children of the future so that they will have the resources, both natural and cultural, to live their lives to the fullest just as our ancestors planned for our survival. While our responsibility is to preserve their options, we do not (and should not) have the ability to make their choices for them. Their indigenous identities will emerge according to a plan not of our making.

While the details of my children's future are beyond my knowledge, I am confident that Iris, born on the first day of the new millennium, will continue to blossom into the strong, beautiful flower that her name represents. She will determine for herself what it means to be an indigenous person in the $21^{\text {st }}$ century. Likewise, my son Wanblee will soar like the eagle that he is and will explore new horizons and new ways of being indigenous in a global society. He will be a leader in a new generation of indigenous people who are indeed "Hot Stuff."

\section{References}

Barkdull, C. 'Exploring intersections of identity with Native American women leaders.' Affilia: Journal of Women and Social Work 24, 2 (2009): 120-136. 
Braun, J. (2008). 'What's in a name? Tribal colleges cultivate students' cultural identity.' Tribal College Journal 19, 3 (2008): 14-19.

Carpenter, C. 'Detecting Indianness: Gertrude Bonnin's investigation of Native American identity.' Wicazo Sa Review 20, 1 (2005): 139-159.

Cuillier, D. \& Ross, S.D. 'Gambling with identity: Self-representation of American Indians on official tribal websites.' The Howard Journal of Communications 18 (2007): 197-219.

Horse, R. G. (2005). 'Native American Identity.' New Directions for Student Services 109 (2005): 61-68.

Kenyon, D.B. \& Carter, J.S. 'Ethnic Identity, Sense of Community, and Psychological Well-being Among Northern Plains American Indian Youth.' Journal of Community Psychology 39, 1 (2011): 1-9.

LeValdo-Gayton, R. 'Jacob as Tonto: Perpetuating Stereotypes that Further Marginalize Natives.' Journal of Mass Media Ethics 26, 3 (2011): 250-253.

Lee, L. 'Navajo Cultural Identity: What can the Navajo Nation Bring to the American Indian Identity Discussion Table?' Wicazo Sa Review 21, 2 (2006): 79-103. 